\title{
Pediatric rhegmatogenous retinal detachment: a review
}

\section{Desprendimiento de retina regmatógeno pediátrico: una revisión}

\author{
Mario Carranza-Casas*, Mariana López-Martínez, Enrique Ariza-Camacho, Rodrigo Matsui-Serrano, \\ Jorge E. Aceves, and Federico Graue-Wiechers \\ Instituto de Oftalmología Conde de Valenciana, Mexico City, Mexico
}

\begin{abstract}
Rhegmatogenous retinal detachment in children and adolescents is a challenging but relatively rare disorder that differs from its adult counterpart in terms of anatomical features, etiology, management, and prognosis. In this article, the clinical and etiopathogenic characteristics are highlighted, and an update is made on its surgical management. The aim is to provide a knowledge base on the benefits, risks and prognosis of rhegmatogenous retinal detachment surgery in children.
\end{abstract}

Keywords: Pediatric retinal detachment. Children. Pediatric rhegmatogenous retinal detachment.

\section{Resumen}

El desprendimiento de retina regmatógeno en niños y adolescentes es una situación desafiante, pero relativamente rara, que difiere de su contraparte en los adultos en cuanto a características anatómicas, etiología, manejo y pronóstico. En este artículo se destacan las características clínicas y etiopatogénicas, y se realiza una actualización sobre su manejo quirúrgico. El propósito es revisar en detalle dichas características, los factores de riesgo y la técnica de reparación inicial. Se busca proporcionar una base de conocimiento sobre los beneficios, los riesgos y el pronóstico de la cirugía de desprendimiento de retina regmatógeno en niños.

Palabras clave: Desprendimiento de retina. Niños. Desprendimiento de retina regmatógeno pediátrico.

\section{Introduction}

Rhegmatogenous retinal detachment (RRD) in children and adolescents is a challenging but relatively rare situation that differs from its adult counterpart in terms of anatomical features, etiology, management, and prognosis. The purpose of this systematic review is to review the clinical data, underlying factors, and repair techniques. The aim is to provide a knowledge base on the benefits, risks and prognosis of RRD surgery in children, as well as to compare the anatomical Correspondence:

*Mario Carranza-Casas

Chimalpopoca 14

Col. Obrera

Date of reception: 08-10-2020

CP 06800, Mexico City, Mexico

E-mail: mcc.9105@gmail.com

Date of acceptance: 12-05-2021

DOI: 10.24875/RMOE.M21000196

2604-1731/๑ 2021 Sociedad Mexicana de Oftalmología. Published by Permanyer. This is an open access article under the CC BY-NC-ND license (http://creativecommons.org/licenses/by-nc-nd/4.0/). and functional results of national and international reports on this disorder. Although many cases have unsatisfactory results, careful and informed management can preserve vision and improve the quality of life of these patients.

\section{Literature review method}

A review of the literature was performed using the PubMed database. A search strategy with the terms $\mathrm{MeSH}$ was used with the Boolean operators AND and 
OR as follows: ("Pediatric Rhegmatogenous Retinal Detachment" [Mesh] OR "Rhegmatogenous Retinal Detachment Children" [Mesh]) AND "Pediatric Retinal Detachment" [Mesh]. We obtained a total of 68 articles. The search was limited to articles in English published from 1998 to August 2020. An additional literature review was performed on included articles and key references were added, including data from an article in press by the authors of this review. After reviewing the abstracts, we eliminated repeated articles, case reports, letters to the editor, book chapters, and articles that considered only one associated disorder (Stickler syndrome or atopic dermatitis). Likewise, articles that mainly dealt with non-rhegmatogenous retinal detachments or that included patients older than 18 years were eliminated. There were a total of 32 publications reviewed.

\section{Definition}

RRD is the separation of the neurosensory retina from the retinal pigment epithelium caused by a retinal tear $^{1}$. The pediatric subgroup with this condition has been defined with age ranges between birth and 18 years ${ }^{1}$. Although some series take 15 or 16 years as the upper limit, in general it can be defined as any RRD in children under 18 years of age.

\section{Epidemiology}

The reported incidence of pediatric RRD in the general population is $0.38-0.69$ per 100,000 inhabitants, representing $0.5-8 \%$ of all retinal detachments and $2-6 \%$ of $\mathrm{RRD}^{1,2}$. The mean age at diagnosis reported in the literature ranged from 8.3 to 15.3 years. The literature consistently reports a higher prevalence in males: between $63 \%$ and $88 \%$ of detachments are observed in men. This is explained because they have greater exposure to risk activities for ocular trauma, which is one of the main predisposing factors for suffering from $\mathrm{RRD}^{3}$. No differences in incidence have been reported between races ${ }^{4}$. Tables 1-3 show the epidemiological, clinical and surgical data in a comparative way between the series included in this review.

\section{Clinical presentation and natural history}

RRDs in children present with poorer visual acuity, a higher probability of macular involvement, and higher rates of proliferative vitreoretinopathy (PVR) compared to adults ${ }^{5,6}$. The presence of systemic and ocular comorbidity, the characteristics of the pediatric eye, the lack of cooperation for examination and the difficulty with postoperative positioning make management more complex ${ }^{5-7}$. Unlike adults, progression is usually slow, with subacute or late-detected visual loss ${ }^{6,7}$. Younger children have worse results due to the chronicity of the detachment at the time of diagnosis, since their immature cognitive functioning makes it difficult to recognize visual symptoms $s^{4,8}$. A low clinical suspicion of this disease and the difficulty of evaluating the peripheral retina at this age contribute to the delay ${ }^{6}$. This reaffirms the importance of performing an adequate periodical dilated ophthalmological examination, particularly in patients with risk factors ${ }^{1,2}$.

Children have a higher prevalence of macular involvement at diagnosis than adults ${ }^{4-10}$, and this is one of the most relevant visual predictors in any $R_{R D}^{3,4}$. Macular involvement rates vary between $45.4 \%$ and 91.4\%. Pediatric RRD is also accompanied by PVR in a higher percentage than in adults, ranging from $11.4 \%$ to $46.6 \%$ of cases. It should be mentioned that the rating scale used in each report may differ and skew the results. The increased activity and cell proliferation inherent in pediatric age, as well as the chronicity of the detachment, are the causes of the frequency of this complication and the subsequent worsening of surgical results $^{8-11}$. Bilateral detachments are also more frequent in children, ${ }^{12}$ ranging from $2.2 \%$ to $17.5 \%$ of cases at the time of diagnosis. Detachments differ from those observed in adults, with demarcation lines, funnel arrangement and retinal macrocysts that reflect chronicity ${ }^{1,2,12}$. Secondary to the previously mentioned reasons, a high percentage of detachments in minors, between $20 \%$ and $75 \%$, are total ${ }^{1,2}$. It is common to find retinal tears and peripheral retinal degenerations in the contralateral eye of these patients, with a prevalence of up to $90 \%$. This increases the risk of a consecutive $R R D$, so it is vital to examine both eyes with emphasis on evaluating the retinal periphery ${ }^{12}$.

\section{Etiology and risk factors}

Most RRDs in adults are associated with posterior vitreous detachment, which is absent in pediatric cas$\mathrm{es}^{6,7}$. Therefore, there is always an additional causative factor ${ }^{7,14,15}$. The "idiopathic" cases could be due to the fact that this age group does not express all the characteristics of the commonly associated diseases, or it could be related to an unacknowledged trauma. However, the evidence indicates that in all cases there is an underlying etiology, although it is not initially 
Table 1. Epidemiological and demographic data reported in the different studies reviewed

\begin{tabular}{|c|c|c|c|c|c|c|c|}
\hline Series & Patients & Eyes & $\begin{array}{c}\text { Age range, } \\
\text { years }\end{array}$ & $\begin{array}{l}\text { Average } \\
\text { age, years }\end{array}$ & Male & Bilateral & Total RRD \\
\hline Carranza, 2021 & 215 & 242 & $0-18$ & 11.2 & $66 \%$ & $12.5 \%$ & $28.9 \%$ \\
\hline Chen, 2020 & 102 & 112 & $0-18$ & 12.2 & $75 \%$ & $9.8 \%$ & $23.2 \%$ \\
\hline Smith, 2019 & 191 & 212 & $0-18$ & 10.5 & $75 \%$ & $9.9 \%$ & $61 \%$ \\
\hline Tsai, 2018 & 152 & 171 & $0-18$ & 14.2 & $76 \%$ & $12.5 \%$ & NR \\
\hline Read, 2018* & 206 & 231 & $0-15$ & 7.3 & $74 \%$ & $12.1 \%$ & NR \\
\hline McElnea, 2017 & 24 & 28 & $0-16$ & 11.6 & $63 \%$ & $16.6 \%$ & NR \\
\hline Agarkar, 2017 & 9 & 12 & $0-16$ & 12 & $100 \%$ & $33.3 \%$ & $75 \%$ \\
\hline Huang, 2017 & 86 & 86 & $0-18$ & 12.9 & $77 \%$ & $0 \%$ & $25.6 \%$ \\
\hline Fong, 2016 & 47 & 49 & $0-18$ & 13.8 & $60 \%$ & $4.2 \%$ & NR \\
\hline Gurler, 2015 & 29 & 30 & $0-18$ & 12.6 & $79 \%$ & $3.4 \%$ & NR \\
\hline Errera, 2015 & 99 & 104 & $0-18$ & 12 & $80 \%$ & $5.0 \%$ & NR \\
\hline Al-Zaaidi, 2013 & 148 & 166 & $0-16$ & 8.3 & $70 \%$ & $12.1 \%$ & $65.4 \%$ \\
\hline Rahimi, $2013^{*}$ & 77 & 77 & $0-18$ & 12.5 & $73 \%$ & $0 \%$ & NR \\
\hline Oono, 2012 & 44 & 48 & $0-15$ & 12.3 & $88 \%$ & $9 \%$ & $14.5 \%$ \\
\hline Soheilian, 2009 & 108 & 127 & $0-18$ & 12.1 & $81 \%$ & $17.5 \%$ & NR \\
\hline Wang, 2008 & 107 & 111 & $0-18$ & 13.7 & $75 \%$ & $3.7 \%$ & $20.7 \%$ \\
\hline Gonzales, 2008 & 45 & 46 & $0-18$ & 9.8 & $71 \%$ & $2.2 \%$ & $58 \%$ \\
\hline Wadhwa, 2008 & 216 & 230 & $0-18$ & 11.1 & $82 \%$ & $6.4 \%$ & NR \\
\hline Lee, 2008 & 82 & 88 & $0-16$ & 14 & $73 \%$ & $7.3 \%$ & NR \\
\hline Wang, 2007 & 33 & 33 & $0-18$ & 11 & $76 \%$ & $0 \%$ & $55 \%$ \\
\hline Rumelt, 2006* & 127 & 144 & $0-18$ & 10.8 & $73 \%$ & $13.3 \%$ & NR \\
\hline Chen, 2006 & 32 & 35 & $0-15$ & 12.4 & $75 \%$ & $9.3 \%$ & NR \\
\hline Chang, 2005 & 146 & 152 & $0-18$ & 13.1 & $70 \%$ & $4.1 \%$ & $31.60 \%$ \\
\hline Wang, 2005 & 278 & 296 & $0-18$ & 14.6 & $74 \%$ & $6.4 \%$ & $27.40 \%$ \\
\hline Yokoyama, 2004 & 49 & 55 & $0-15$ & 12 & $86 \%$ & $6.6 \%$ & NR \\
\hline Sarrazin, 2004 & 56 & 60 & $0-18$ & 11.6 & $84 \%$ & $7.1 \%$ & $55 \%$ \\
\hline Weinberg, 2003 & 34 & 39 & $0-18$ & 10.5 & $79 \%$ & $14.7 \%$ & $48.70 \%$ \\
\hline Fivgas, 2001 & 27 & 29 & $0-18$ & 9.6 & $70 \%$ & $7.4 \%$ & NR \\
\hline Akabane, 2001 & 28 & 32 & $0-15$ & 12.8 & $71 \%$ & $14.2 \%$ & NR \\
\hline Haring, 1998 & 31 & 33 & $0-18$ & 15.3 & $55 \%$ & $6.4 \%$ & $3 \%$ \\
\hline
\end{tabular}

RRD: rhegmatogenous retinal detachment; NR: not reported.

*Some cases of other types of retinal detachment were included.

apparent ${ }^{1,2}$. The etiological factors reported in the series reviewed may show overlapping, since many patients have more than one risk factor ${ }^{12,14,15}$. For example, it is more common for trauma to cause RRD in children with a long axial length or a history of intraocular surgery ${ }^{12}$. It is also likely that congenital abnormalities, such as Stickler syndrome, are accompanied by pathological myopia or previous intraocular surgery ${ }^{13}$. 
Rev Mex Oftalmol (Eng). 2021;95(6)

Table 2. Clinical data and causal associations of detachments in the different studies reviewed

\begin{tabular}{|c|c|c|c|c|c|c|c|c|}
\hline Series & Trauma & Myopia & $\begin{array}{c}\text { Definition of } \\
\text { myopia }\end{array}$ & $\begin{array}{l}\text { Congenital } \\
\text { anomalies }\end{array}$ & $\begin{array}{l}\text { Previous intraocular } \\
\text { surgery }\end{array}$ & Dialysis & $\begin{array}{c}\text { Macular } \\
\text { involvement }\end{array}$ & PVR \\
\hline Carranza, 2021 & $38.1 \%$ & $34.7 \%$ & $>-1 \mathrm{D}$ & $6 \%$ & $17.8 \%$ & $9 \%$ & $86 \%$ & $43 \%$ \\
\hline Chen, 2020 & EXC & $47.1 \%$ & $>-1 \mathrm{D}$ & $50 \%$ & $11.8 \%$ & $2.7 \%$ & $60.7 \%$ & NR \\
\hline Smith, 2019 & $37 \%$ & $33 \%$ & NR & $23 \%$ & $18 \%$ & $17 \%$ & $91 \%$ & $40 \%$ \\
\hline Tsai, 2018 & $14.6 \%$ & $40.9 \%$ & $>-2 \mathrm{D}$ & $11.1 \%$ & $11.7 \%$ & $1.8 \%$ & $78.9 \%$ & $16.4 \%$ \\
\hline Read, 2018* & $33 \%$ & $29 \%$ & NR & NR & NR & NR & $N R$ & $68 \%$ \\
\hline McElnea, 2017 & $50 \%$ & $40.3 \%$ & NR & NR & NR & $21.4 \%$ & $64.3 \%$ & $42.9 \%$ \\
\hline Agarkar, 2017 & $N R$ & $58.3 \%$ & $\mathrm{AL}>24.5 \mathrm{~mm}$ & NR & $100 \%$ & $0 \%$ & $83.3 \%$ & $16.6 \%$ \\
\hline Huang, 2017 & $27.9 \%$ & $55.8 \%$ & $>-1 \mathrm{D}$ & $39.5 \%$ & $17.4 \%$ & $5.8 \%$ & $75.6 \%$ & $46.6 \%$ \\
\hline Fong, 2016 & $8.5 \%$ & $66.7 \%$ & $>-6 \mathrm{D}$ & $17 \%$ & NR & $12.3 \%$ & $57.1 \%$ & $36.7 \%$ \\
\hline Gurler, 2015 & $36.6 \%$ & $40 \%$ & $>-6 \mathrm{D}$ & $6.6 \%$ & NR & $6.6 \%$ & NR & $46.6 \%$ \\
\hline Errera, 2015 & $39 \%$ & $42 \%$ & $>-1 \mathrm{D}$ & $20.1 \%$ & $3.8 \%$ & $53.8 \%$ & $60.5 \%$ & $9.6 \%$ \\
\hline Al-Zaaidi, 2013 & $43 \%$ & $30.7 \%$ & $>-1 \mathrm{D}$ & $31 \%$ & $40 \%$ & NR & $78.4 \%$ & $33 \%$ \\
\hline Rahimi, 2013* & $90 \%$ & $6 \%$ & $>-4 \mathrm{D}$ & NR & $53 \%$ & $4 \%$ & NR & $14 \%$ \\
\hline Oono, 2012 & $38 \%$ & $41.6 \%$ & $>-3 \mathrm{D}$ & $10.4 \%$ & $0 \%$ & $14.5 \%$ & $33.3 \%$ & $15 \%$ \\
\hline Soheilian, 2009 & $44.3 \%$ & $29.1 \%$ & $>-3 \mathrm{D}$ & $39.3 \%$ & $7.9 \%$ & $N R$ & $80 \%$ & $45 \%$ \\
\hline Wang, 2008 & EXC & $100 \%$ & $>-6 \mathrm{D}$ & $11.7 \%$ & NR & $5.4 \%$ & $77.4 \%$ & $39.6 \%$ \\
\hline Gonzales, 2008 & $43 \%$ & $17 \%$ & $>-4 \mathrm{D}$ & $21 \%$ & $61 \%$ & $6.5 \%$ & $83 \%$ & $59 \%$ \\
\hline Wadhwa, 2008 & $34 \%$ & $14 \%$ & NR & NR & NR & NR & $98.2 \%$ & $44.8 \%$ \\
\hline Lee, 2008 & $53 \%$ & $17 \%$ & $>-6 \mathrm{D}$ & $27 \%$ & $2.20 \%$ & $44 \%$ & $66 \%$ & NR \\
\hline Wang, 2007 & $100 \%$ & $N R$ & NR & NR & NR & $9 \%$ & $70 \%$ & $64 \%$ \\
\hline Rumelt, 2006* & $42 \%$ & $11 \%$ & $>-6 \mathrm{D}$ & $36 \%$ & $10 \%$ & $1.40 \%$ & $77 \%$ & $12 \%$ \\
\hline Chen, 2006 & $23 \%$ & $23 \%$ & $>-3 D$ & $34 \%$ & $3 \%$ & NR & $91.4 \%$ & $11.4 \%$ \\
\hline Chang, 2005 & $33 \%$ & $37.5 \%$ & $>-4 \mathrm{D}$ & $11.80 \%$ & $5.90 \%$ & $10.50 \%$ & $73 \%$ & $18.4 \%$ \\
\hline Wang, 2005 & $30.7 \%$ & $38 \%$ & $>-6 \mathrm{D}$ & $17 \%$ & $5 \%$ & $6.80 \%$ & $80 \%$ & $45.6 \%$ \\
\hline Yokoyama, 2004 & $27 \%$ & $25 \%$ & $>-4 \mathrm{D}$ & $26 \%$ & $2 \%$ & $27 \%$ & NR & $22 \%$ \\
\hline Sarrazin, 2004 & $100 \%$ & NR & NR & NR & NR & $3.33 \%$ & $58 \%$ & $3 \%$ \\
\hline Weinberg, 2003 & $36 \%$ & NR & NR & $41 \%$ & $51 \%$ & $5.12 \%$ & $74 \%$ & $31 \%$ \\
\hline Fivgas, 2001 & EXC & $34 \%$ & $>-4 \mathrm{D}$ & $27.60 \%$ & $34 \%$ & $21 \%$ & $79 \%$ & $45 \%$ \\
\hline Akabane, 2001 & $22 \%$ & $38 \%$ & $>-4 \mathrm{D}$ & 18.7 & $9.40 \%$ & $6.30 \%$ & NR & $37.5 \%$ \\
\hline Haring, 1998 & $24 \%$ & $42 \%$ & $>-3 \mathrm{D}$ & NR & $9.10 \%$ & $42.40 \%$ & $45.4 \%$ & NR \\
\hline
\end{tabular}

D: diopters; EXC: patients with a history of trauma were excluded; AL: axial length; NR: not reported; PVR: proliferative vitreoretinopathy. * Some cases of other types of retinal detachment were included.

\section{Trauma}

The most prevalent factor in most series is ocular trauma $^{1,2}$. It is related to $22 \%$ to $53 \%$ of pediatric RRDs.
Detachment in these cases is generated by an indirect mechanism related to deformation of the globe or direct damage to the ocular wall ${ }^{3,4}$. The formation of peripheral tears opposite to the impact site is the result of 
Table 3. Surgical data and results from the different studies reviewed

\begin{tabular}{|c|c|c|c|c|c|c|c|c|c|}
\hline Series & $\begin{array}{c}\text { Series } \\
\text { duration, } \\
\text { years }\end{array}$ & $\begin{array}{c}\text { Operated } \\
\text { eyes }\end{array}$ & $\begin{array}{l}\text { Minimum } \\
\text { follow-up, } \\
\text { months }\end{array}$ & $\begin{array}{l}\text { Average } \\
\text { follow-up, } \\
\text { months }\end{array}$ & $\begin{array}{l}\text { Average } \\
\text { number of } \\
\text { surgeries } \\
\text { per eye }\end{array}$ & $\begin{array}{l}\text { Lens } \\
\text { surgery }\end{array}$ & $\begin{array}{l}\text { Anatomical } \\
\text { success }\end{array}$ & $\begin{array}{l}\text { Functional } \\
\text { success }\end{array}$ & $\begin{array}{l}\text { Definition } \\
\text { of } \\
\text { functional } \\
\text { success }\end{array}$ \\
\hline Carranza, 2021 & 16 & 168 & 3 & 51.9 & 1:44 AM & $22.6 \%$ & $62 \%$ & $54 \%$ & $\geq 20 / 200$ \\
\hline Chen, 2020 & 4 & 112 & NR & NR & NR & NR & NR & NR & NR \\
\hline Smith, 2019 & 14 & 212 & 3 & 36.3 & 1:34 AM & $20 \%$ & $78 \%$ & NR & NR \\
\hline Tsai, 2018 & 20 & 171 & 6 & 37.8 & 1:22 AM & NR & $86.7 \%$ & $81.6 \%$ & $\geq 20 / 200$ \\
\hline Read, 2018* & 11 & 178 & 3 & 48 & NR & $38.7 \%$ & $62 \%$ & $25 \%$ & $\geq 20 / 200$ \\
\hline McElnea, 2017 & 8 & 28 & NR & NR & 3.0 & $34.6 \%$ & $84.6 \%$ & $25 \%$ & $\geq 20 / 40$ \\
\hline Agarkar 2017, & 11 & 10 & NR & 45.5 & 1.2 & NR & $83.4 \%$ & $75 \%$ & $\geq 20 / 200$ \\
\hline Huang, 2017 & 5 & 86 & 3 & 46.3 & NR & NR & NR & NR & $\geq 20 / 200$ \\
\hline Fong, 2016 & 12 & 49 & NR & NR & 1:48 AM & $20.4 \%$ & $85.7 \%$ & NR & NR \\
\hline Gurler, 2015 & NR & 30 & 3 & 8 & 1.2 & NR & $83.3 \%$ & $80 \%$ & $\geq 5 / 200$ \\
\hline Errera, 2015 & 13 & 104 & 3 & 25 & 1:25 AM & NR & $94 \%$ & NR & NR \\
\hline Al-Zaaidi, 2013 & 10 & 166 & 12 & 40.14 & 1:16 AM & $51.2 \%$ & $78.3 \%$ & $44 \%$ & $\geq 20 / 200$ \\
\hline Rahimi, 2013* & 5 & 77 & NR & NR & 1.8 & NR & $62.3 \%$ & $51.4 \%$ & $\geq 5 / 200$ \\
\hline Oono, 2012 & 11 & 48 & 3 & 24 & 1:46 AM & NR & $95.8 \%$ & $85.4 \%$ & $\geq 20 / 200$ \\
\hline Soheilian, 2009 & 8 & 127 & 6 & 34 & 1:55 AM & $40.1 \%$ & $74.9 \%$ & $37 \%$ & $\geq 20 / 200$ \\
\hline Wang, 2008 & 20 & 111 & 6 & NR & 1:12 AM & $9.9 \%$ & $90.9 \%$ & $72.9 \%$ & $\geq 20 / 200$ \\
\hline Gonzales, 2008 & 5 & 46 & 3 & 20.4 & NR & $55 \%$ & $78 \%$ & $44 \%$ & $\geq 20 / 200$ \\
\hline Wadhwa, 2008 & NR & 230 & 3 & 12.3 & 1.98 & NR & $88.7 \%$ & $60 \%$ & $\geq 4 / 200$ \\
\hline Lee, 2008 & 15 & 88 & NR & NR & NR & NR & NR & NR & NR \\
\hline Wang, 2007 & 20 & 33 & 6 & 57.1 & 1:45 AM & $84 \%$ & $36.3 \%$ & $36 \%$ & $\geq 20 / 100$ \\
\hline Rumelt, $2006^{*}$ & 20 & 144 & 1 & 44.28 & 1:55 AM & NR & $52 \%$ & $37 \%$ & $\geq 20 / 400$ \\
\hline Chen, 2006 & 9 & 35 & NR & NR & 1.4 & $25.7 \%$ & $80 \%$ & $37.1 \%$ & $\geq 20 / 50$ \\
\hline Chang, 2005 & 14 & 152 & 6 & 48.3 & 1.5 & NR & $78.3 \%$ & NR & NR \\
\hline Wang, 2005 & 20 & 296 & 6 & 51 & 1:34 AM & $12.1 \%$ & $85 \%$ & $51.7 \%$ & $\geq 20 / 100$ \\
\hline Yokoyama, 2004 & 14 & 55 & 12 & 80 & 1.2 & NR & $87 \%$ & $73 \%$ & $\geq 20 / 200$ \\
\hline Sarrazin, 2004 & 20 & 55 & 1 & 34.8 & NR & NR & $52.7 \%$ & $28 \%$ & $\geq 20 / 200$ \\
\hline Weinberg, 2003 & 9 & 39 & 3 & 31.1 & 1.6 & NR & $79 \%$ & $15 \%$ & NR \\
\hline Fivgas, 2001 & 6 & 29 & 4 & 21.4 & 2.2 & NR & $72 \%$ & $41 \%$ & $\geq 20 / 800$ \\
\hline Akabane, 2001 & 5 & 32 & 6 & 16.4 & 1.1 & NR & $93.8 \%$ & NR & NR \\
\hline Haring, 1998 & 14 & 33 & 3 & 106.8 & 1:15 AM & NR & $100 \%$ & $60.6 \%$ & $\geq 20 / 40$ \\
\hline
\end{tabular}

NR: not reported.

*Some cases of other types of retinal detachment were included.

changes in vitreous traction induced by the sudden expansion of the eye ${ }^{3,4}$. In many cases, detachment is diagnosed late, simulating an idiopathic $\mathrm{RRD}^{3,4,16}$; this is due to the strong vitreoretinal adherence in young patients and the absence of posterior vitreous detachment $^{1-4}$. On the other hand, traumatic RRDs are 
associated with concomitant lesions in other ocular structures and PVR, and therefore the prognosis is usually poor ${ }^{3,4,11,16}$. Except when there is evidence of endophthalmitis or an intraocular foreign body, repair of a post-traumatic RRD should be performed 4 to 7 days after the event; the aim is to achieve the highest vitreous liquefaction before attempting to induce a posterior vitreous detachment during the procedure ${ }^{3,4,6,16}$. Early surgery could increase the risk of bleeding due to congestion of the uveal tissues, while a longer delay increases the risk of fibrovascular proliferation and makes management difficult ${ }^{7,16}$. RRDs associated with penetrating trauma have a worse prognosis than those caused by a blunt injury, although there are reports that conclude otherwise. One possible explanation is that indirect shock waves can cause retinal dialysis and choroidal ruptures not detected initially, leading to a chronic RRD with a worse outcome $3,4,7,9,14,16$.

\section{Myopia}

Myopia is the second most reported factor ${ }^{17}$, found in $14 \%$ to $58.3 \%$ of pediatric RRDs. The definition of myopia varies significantly between the different studies (Table 2) ${ }^{17}$. This condition is more common in adolescents, its incidence increases with age ${ }^{4,12,17}$ and its prevalence is also increasing globally, mainly in Asian populations ${ }^{4,12,17}$. Myopia causes retinal detachment since there is a higher prevalence of peripheral retinal degenerations, poor choroid pumping, pathological vitreous, and early posterior vitreous detachment ${ }^{14,17}$. Detachments associated with myopia in adolescents probably have a pathogenesis and characteristics similar to those detachments observed in adults, so compared to other etiologies with comorbidities or complex mech-

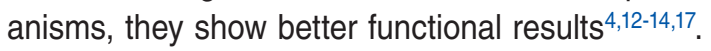

\section{Congenital and developmental abnormalities}

There are abnormalities present at birth or that manifest during early development that predispose to RRD during life ${ }^{1,2}$. They are usually accompanied by vitreous alterations, including abnormal liquefaction and pathological vitreous adhesion, as well as predisposing lesions from an early age $\mathrm{e}^{12,18,19}$. The prevalence of these anomalies is reported between $6 \%$ and $39 \%$, and bilaterality is the norm ${ }^{19}$. In the case of detachments in these patients there is a higher frequency of macular involvement and chronic RRD ${ }^{9,19}$. They present with more severe PVR, poorer prognoses and a greater number of surgical procedures ${ }^{9,19}$. The conditions most frequently associated with pediatric RRD are briefly discussed below.

\section{STICKLER SYNDROME}

stickler syndrome is the most common inherited cause of RRD in children ${ }^{19}$. There are several types, from I to $\mathrm{VI}$, associated with mutations that code for different types of collagen ${ }^{1,2}$. Type I, which corresponds to $85 \%$ of diagnoses, is caused by mutations in the COL2A1 gene and is transmitted in an autosomal dominant manner ${ }^{1,2}$. This disease manifests with congenital high myopia, high risk of RRD, early deafness and generalized arthropathy ${ }^{1,2}$. In addition, patients have early cataracts, peripheral lattice degeneration and retinal tears in up to $90 \%^{1,2}$. The vitreous of these patients is anomalous, optically empty and with retrolental membranous characteristics ${ }^{1,2}$. Different mutations in the same gene or in other collagen variants can cause similar phenotypes, such as Kniest dysplasia and Marshall syndrome, which also carry a high risk of pediatric $R_{R D}{ }^{1,2}$. Stickler syndrome and its variants have been associated with giant tears as causative lesions and a worse functional outcome after repair ${ }^{13}$.

\section{VITREORETINOPATHIES ASSOCIATED WITH CHROMOSOME $5 Q$}

Wagner's disease, Jansen's disease, and erosive vitreoretinopathy are conditions within the same pathological spectrum caused by autosomal dominant mutations in the CSPG2/VCAN ${ }^{1,2}$ gene. The affected gene is located on chromosome 5 and codes for the proteoglycan versican of the extracellular matrix, involved in the maintenance of the vitreous structure ${ }^{1,2}$. These diseases are characterized by moderate myopia and vitreous degeneration with equatorial avascular veils $^{1,2}$. They are associated with $R R D$ in adolescence, so they can be found in pediatric RRD series ${ }^{1,2}$.

\section{MARFAN SYNDROME}

autosomal dominant syndrome in which the gene encoding fibrillin, a protein that participates in the elastin scaffold is altered ${ }^{1,2}$. Its systemic findings include long limbs, arachnodactyly, hyperextensible joints, and vascular defects ${ }^{1,2}$. The most common ocular manifestation is lens subluxation, in $50-80 \%$ of those affect$\mathrm{ed}^{1,2}$. Axial myopia is also common: more than $20 \%$ have myopia greater than 7 diopters ${ }^{1,2}$. The myopia 
itself and the high rates of intraocular surgery determine a higher prevalence of pediatric $R_{R D} D^{1,2}$.

\section{X-LINKED JUVENILE RETINOSCHISIS}

it is an X-linked disease (observed predominantly in males) characterized by radial streaks in the macula secondary to foveal schisis, as well as by peripheral retinal separation ${ }^{1,2}$. It is caused by mutations in the RS1 gene that encodes retinoschina, an essential protein in cell adhesion between photoreceptors and bipolar cells $\mathbf{s}^{1,2}$. Foveal schisis causes loss of central vision, but it is peripheral schisis that can cause RRD in 5\% to $22 \%$ of cases $^{1,2,14}$. Repair of these detachments is complicated by a hyaloid firmly adhered to the inner wall of the detached retina ${ }^{1,2}$.

\section{Previous intraocular surgery (pseudophakia or aphakia)}

Any intraocular surgery implies alteration and traction of the vitreous, as well as a risk of generating posterior vitreous detachment; this predisposes to a $R_{R D}{ }^{6,7}$. Moreover, aphakic patients lose the support of the vitreous base, which increases the risk of multiple small anterior tears, especially hard to identify in children? The literature reports a variable prevalence, between $2 \%$ and $61 \%$. A large percentage corresponds to children operated on for congenital cataract or for developmental glaucoma ${ }^{4}$; the comorbidity and complications observed in these cases lead to a poorer visual and anatomical prognosis ${ }^{7-9}$.

\section{Retinopathy of prematurity}

Although patients with active retinopathy of prematurity usually have tractional detachments, those that show regression of the disorder may have high rates of rhegmatogenous detachment later in life ${ }^{7}$. This is due to a high risk of developing high myopia, predisposing lesions and vitreous alterations $\mathbf{s}^{1,20}$. The physiopathogenesis of these changes is not clear ${ }^{1,20}$. Cases of RRD with a history of preterm delivery and retinopathy of prematurity have a higher rate of PVR and total detachment, with poorer visual results ${ }^{1,20,21}$.

\section{Young adult retinal dialysis}

Retinal dialysis is a specific type of circumferentially oriented retinal tear, located anterior to the ora serrata within the ciliary epithelium, or posterior to the ora within the retina ${ }^{1,2}$. The most common cause is trauma ${ }^{8,18}$, but a subgroup with an apparent genetic origin has also been described ${ }^{15}$. The latter is known as retinal dialysis of young adults or idiopathic dialysis, and is believed to originate from peripheral cystic degeneration ${ }^{15}$. It is more common in males and tends to be located in the temporal retina of emmetropic eyes during the second or third decade of life ${ }^{15}$. Detachments secondary to dialysis progress slowly and are accompanied by demarcation lines, showing chronicity ${ }^{1,2,15}$. PVR is rare and there are good results with scleral buckle ${ }^{15}$.

\section{Chorioretinal coloboma}

Chorioretinal colobomas are congenital anomalies caused by failure of closure of the embryonic fissure. They are characterized by a sectoral absence of the retina, retinal pigment epithelium, and choroid ${ }^{18}$. They can appear isolated or associated with other alterations, especially colobomas of other ocular layers ${ }^{1,2}$. They can be unilateral or bilateral, and are typically located in the inferotemporal quadrant ${ }^{18}$. They can involve the macula, causing poor visual function ${ }^{1,2}$. A common complication is retinal tears at their borders, which can lead to $R R D^{18}$. Its posterior location usually requires vitrectomy ${ }^{18}$.

\section{Atopic dermatitis}

An association between atopic dermatitis and pediatric RRD has only been described in Asian patients $8,9,22$. The main theory is based on the fact that chronic trauma secondary to recurrent ocular rubbing can cause vitreous alterations, retinal dialysis and predisposing lesions that lead to $\operatorname{RRD}^{8-9,22}$.

\section{Others}

Pediatric RRD has been reported associated with other pathologies ${ }^{1-10}$. Due to the rarity of these reports, their causal association cannot be definitively confirmed. They include Morning Glory anomaly, congenital rubella, congenital cytomegalovirus infection, congenital toxoplasmosis, toxocariasis, pars planitis, acute retinal necrosis, retinoblastoma, Coats disease, Sturge-Weber syndrome, and aniridia. The commonly mentioned associations between buphthalmos, microphthalmos and mental retardation with RRD are probably due to the fact that these conditions are usually accompanied by other congenital anomalies described or previous intraocular surgery ${ }^{1-10}$. 


\section{Assessment and diagnosis}

\section{Medical records}

Evaluation of pediatric patients with RRD should include a detailed history. The most common presentations are visual loss and leukocoria; strabismus and poor fixation have been reported less frequently ${ }^{18}$. Previously referred predisposing factors and possible hereditary syndromes in family history should be investigated ${ }^{1,2}$. The history of ocular trauma should be investigated, since it could be related to the time of evolution of the RRD, which is an indicator of visual prognosis ${ }^{22-28}$. It must be remembered that it is rare for children, especially in those under 6 years of age, to report visual symptoms ${ }^{14,15}$.

\section{Examination}

Visual acuity and refraction are basic data in the examination of pediatric patients with RRD. If necessary, in preverbal children, dilated fundus evaluation will be performed in the operating room under general anesthesia due to lack of cooperation. In case of media opacity or poor dilation, ultrasound can be used as a diagnostic method to confirm detachment or observe other relevant findings ${ }^{1,2}$.

It is common to find lesions in the contralateral eye (in up to $90 \%$ of cases $^{13}$ ), sometimes even detecting a retinal detachment ${ }^{18}$; therefore, it is vital to examine both eyes. The type of causative lesion is variable, and sometimes it is not easy to identify the cause due to difficulty in performing an adequate examination. The horseshoe tear has been described as the most common injury ${ }^{13,23}$, but series agree that lattice degeneration associated or not with atrophic holes are the most common predisposing lesions in children $4,8-10,17,18,24$. The latter are especially frequent in myopic patients, and are associated with a lower risk of developing $\mathrm{PVR}^{9}$. In patients with a history of trauma, there must be a thorough examination looking for retinal dialysis, giant tears or avulsion of the vitreous base ${ }^{3}$. The search for systemic signs of inherited diseases is also essential. Trunk and limb abnormalities, facial abnormalities, hearing loss and cognitive delay, among others, could indicate the presence of a syndrome ${ }^{1,2}$.

\section{Management, results and prognosis}

Treatment is surgical in most cases ${ }^{1-2,26}$ and results vary according to comorbidity, etiology, chronicity and the initial procedure ${ }^{25-28}$; however, they are less satisfactory compared to adults ${ }^{18,19}$. In a patient who already has a history, the risk of RRD in the contralateral eye is approximately $10 \% 24,25$.

\section{Surgical techniques}

Repair in pediatric RRDs follows similar principles to those described in adults, including removal of vitreous traction, drainage of subretinal fluid, and retinopexy with laser or cryotherapy ${ }^{25-28}$. However, there are anatomical and functional differences in the pediatric eye that require specific considerations when choosing the surgical technique $25-28$.

The initial approaches available include scleral buckling, pars plana vitrectomy (PPV), or a combination of both $^{25-28 .}$

Primary scleral buckling is still used in many cases as the initial procedure when there is adequate retinal visualization and no significant $\mathrm{PVR}^{8-10,26}$. It is an extraocular surgery that does not involve manipulation of the vitreous and also avoids the need to reoperate the patient when using silicone tamponade ${ }^{17,18,26}$. In the literature reviewed, primary scleral buckling was performed in a variable number of cases, between $12 \%$ and $86 \%$. This discrepancy corresponds to the different etiologies included in each study ${ }^{26}$. Several studies have reported excellent results with the use of cerclage, particularly in RRD associated with myopia ${ }^{17,26,28-30}$. The efficacy of primary scleral buckling in these cases may be due to a non-liquefied vitreous tamponade effect present in a young eye when the buckle traction is relaxed. This advantage could also be a bias, since this technique is chosen for less complicated detachments ${ }^{18,26}$. Usually they are phakic patients, who do not have posterior tears or significant $\mathrm{PVR}^{25-28}$. The latter is the most frequent cause of episcleral surgery failure ${ }^{18,26}$.

Scleral buckling has been performed both segmental $^{8,25-26}$ and circumferential $\left.\right|^{4,16,17,25-26}$, and the selection of methods and materials vary according to the nature of the detachment, the size of the patient and surgeon's preference ${ }^{25,26}$. There is no consensus on the preference for the location, style or size of the explant, nor on the indication for exodrainage ${ }^{19,25,26}$.

PPV has been increasing in popularity and is the preferred technique in cases of complex, total detachments, with significant PVR, media opacity, posterior lesions, epiretinal membranes or chorioretinal colobomas ${ }^{17-19,23-26}$. Patients in whom the retina cannot be adequately visualized preoperatively usually require 
vitrectomy ${ }^{25-28}$. Post-traumatic RRDs and those associated with congenital anomalies are usually managed with $\mathrm{PPV}^{3}$, which is also the procedure of choice in recurrent cases and in patients with previous intraocular surgery ${ }^{25-28}$. However, it is preferred to avoid PPV whenever possible, for several reasons. First, in children, the vitreous is less liquefied and the posterior hyaloid is strongly adhered to the retinal surface $e^{8,17,23-28}$. The complexity of their separation increases surgical difficulty and predisposes to iatrogenic tears; it is common to have to resort to retinectomies, since the force of the pediatric vitreoretinal interface may prevent the full release of retinal traction $^{23-28}$. Second, PPV may induce secondary cataract, whose morbidity in this age group is significant due to the high risk of amblyopia and the loss of accommodation after surgery ${ }^{23-28}$. Finally, an increased risk of a re-detachment and PVR has been described in patients who underwent PPV22; this may reflect the severity of the detachments in which vitrectomy is chosen rather than a negative influence of it ${ }^{4,16,17}$. Most studies recommend a three-port vitrectomy ${ }^{25-28}$. Ports of entry are placed through the limbus, pars plicata, or pars plana, depending on the age of the child, the size of the eye, and the nature of the detachment ${ }^{25-28}$. During surgery, posterior vitreous detachment should be induced, and it is also imperative to remove the posterior hyaloid as much as possible to minimize the possibility of postoperative vitreous contraction that may cause recurrence, induction of PVR or formation of epiretinal membranes ${ }^{25-28}$. Non-detached vitreous can be difficult to visualize, and triamcinolone acetonide has been used to facilitate identification of the hyaloid ${ }^{22-28}$. In cases of traumatic cataract, lensectomy is indicated ${ }^{1,2}$.

In some cases, PPV combined with scleral buckling has shown higher success rates than PPV alone ${ }^{21}$. Cerclage supports the vitreous base and reduces residual traction caused by vitreous debris near the tear $^{21-28}$. Due to the rigid characteristics of the pediatric vitreous, it can contract and cause recurrence ${ }^{21-28}$. Relaxing these tractions facilitates the reabsorption of the subretinal fluid, possibly reducing the risk of recurrence and improving the prognosis ${ }^{21-28}$. There is more evidence of the advantage of the combined procedure in cases with media opacity, giant or multiple tears, posterior detachments, and significant PVR ${ }^{18}$.

Using tamponade in children is controversial. Although the use of perfluoropropane $e^{4,16,17}$ has been described, considering the possibility of inadequate postoperative cooperation and the intraocular pressure peaks associated with gas tamponade, silicone oil is preferred in children. The latter is indicated in cases of reoperation and extensive PVR $4,9,16,19$. Poor results associated with the use of silicone as tamponade have been documented, although this probably reflects the severity of the detachments in which it was chosen rather than a direct negative effect ${ }^{11}$. It is recommended to remove the silicone after a minimum of 3 months for visual rehabilitation and remembering the complications of its use, such as the risk of glaucoma and band keratopathy ${ }^{18}$.

\section{Results}

Anatomical success (defined as a fully applied retina in the absence of silicone tamponade) was achieved in more than $60 \%$ of the patients in most of the reviewed studies (Tables 1 and 2) ${ }^{31,32}$. Due to the difficulty in the adequate visual and refractive assessment in children under 6 years of age, the anatomical results become important as they have a strong correlation with long-term visual capacity ${ }^{4,16,17}$. The clinical characteristics that could predict anatomical success are the absence of macular involvement and the sub totality of the detachment $t^{4,7,9,16,17}$. Likewise, better anatomical results were observed in eyes with myopia 9 . In contrast, the presence of significant PVR and a history of intraocular surgery were predictors of failure $e^{4,7-10}$.

It is difficult to reliably report a comparison of visual outcomes in pediatric patients, and visual success was defined variably between series. In the included studies, the most common definition of functional success was best-corrected acuity in the last examination $\geq 20 / 200$ (Snellen). Among the groups that used this definition, the average visual success was $54 \%$.

When evaluating visual success, the absence of macular involvement, the sub totality of the RRD and associated myopia were positive predictors. Conversely, predictors of poor outcome were poor preoperative vision, significant PVR, prior intraocular surgery, total detachment, penetrating trauma, congenital anomalies, younger age at diagnosis, need for vitrectomy and the use of silicone oil ${ }^{4,8-11,16,17}$.

The bibliographic review reveals that age is a determining factor of outcomes ${ }^{26-28}$. Children have a worse visual prognosis due to the higher frequency of congenital anomalies ${ }^{4,7}$, retinopathy of prematurity or penetrating trauma ${ }^{9,26}$. The late diagnosis in children is reflected by higher rates of macular involvement, total detachment and significant PVR ${ }^{4,16-17,26}$. Older children 
have a lower prevalence of macular involvement and therefore have better prognosis ${ }^{14}$.

Surgical results also vary depending on the etiology, as already mentioned in the sections dedicated to predisposing factors. Although some studies have cast doubt on this, ${ }^{27}$ there is agreement in the literature regarding that the best outcomes are observed in RRD related to myopia ${ }^{4,12-14,16,17}$. The causes of this correlation include that they have a relatively healthy vitreous compared with other etiologies such as trauma and congenital anomalies ${ }^{7-9,14,19}$. Another explanation argues that in myopic eyes there are lower concentrations of cytokines and growth factors within the retinal pigment epithelium ${ }^{14,27}$. It is likely that these patients represent a subgroup that responds adequately to primary scleral buckling ${ }^{14,24}$. Furthermore, it is important to mention the correlation between myopia and RRD in older children ${ }^{4,16,17}$. The above could be a confounding variable, since visual evaluation is more reliable in the latter, there is greater postoperative cooperation and, as already mentioned, they tend to have better outcomes ${ }^{4,16,17}$.

In pediatric patients there is always a high risk of amblyopia, even when anatomical success is achieved. Therefore, some authors suggest postoperative occlusion in all patients under 10 years of age, as well as visual rehabilitation and refractive correction performed as intensively as possible $3-4,16,17$.

\section{Conclusions}

Compared to RRDs in adults, children have different etiologies and differ in presentation, characteristics, and prognosis. Repair poses unique challenges for the surgeon due to its characteristics as well as the anatomy and physiology of the pediatric eye. Although visual outcomes are poor compared to the adult population, the high rate of bilateral detachments and pathology in the contralateral eye make it extremely important to be able to recognize and treat these children early.

In the future, new surgical approaches and instruments, alternative and adjunctive treatments such as stem cell therapy, gene replacement therapy, retinal transplantation and the development of new retinal prostheses, together with advances in visual aids, may improve the functional outcomes of these children.

\section{Funding}

No funding was required for this article.

\section{Conflicts of interest}

The authors have no conflict of interest to report

\section{Ethical disclosures}

Protection of human and animal subjects. The authors declare that no experiments were performed on humans or animals for this study.

Confidentiality of data. The authors declare that they have followed the protocols of their Institution on the publication of patient data.

Right to privacy and informed consent. The authors have obtained the written informed consent of the patients or subjects mentioned in the article. The corresponding author is in possession of this document.

\section{References}

1. Nuzzi R. Lavia C, Spinetta R. Paediatric retinal detachment: a review. Int J Ophthalmol. 2017;10):1592-03.

2. Wenick AS, Barañano DE. Evaluation and management of pediatric rhegmatogenous retinal detachment. Saudi J Ophthalmol. 2012; 26:255-63.

3. Sarrazin L, Averbukh E, Halpert M, Hemo I, Rumelt S. Traumatic paediatric retinal detachment: a comparison between open and closed globe injuries. Am J Ophthalmol. 2004;137:1042-49.

4. Wang NK, Tsai CH, Chen YP, Yeung L, Wu WC, Chen TL, et al. Paediatric rhegmatogenous retinal detachment in East Asians. Ophthalmology. 2005;112:1890-5.

5. Häring $\mathrm{G}$, Wiechens $\mathrm{B}$. Long-term results after scleral buckling surgery in uncomplicated juvenile retinal detachment without proliferative vitreoretinopathy. Retina. 1998;18:501-5.

6. Rumelt S, Sarrazin L, Averbukh E, Halpert M, Hemo I. Paediatric vs adult retinal detachment. Eye (Lond). 2007;21:1473-8.

7. Gonzales CR, Singh S, Yu F, Kreiger AE, Gupta A, Schwartz SD. Pediatric rhegmatogenous retinal detachment: clinical features and surgical outcomes. Retina. 2008;28:847-52.

8. Yokoyama T, Kato T, Minamoto A, Sugihara A, Imada M, Kuwabara R, et al. Characteristics and surgical outcomes of paediatric retinal detachment. Eye (Lond). 2004;18:889-92.

9. Chang PY, Yang CM, Yang CH, Huang JS, Ho TC, Lin CP, et al. Clinical characteristics and surgical outcomes of paediatric rhegmatogenous retinal detachment in Taiwan. Am J Ophthalmol. 2005;139:1067-72.

10. Akabane N, Yamamoto S, Tsukahara I, Ishida M, Mitamura Y, Yamamoto $\mathrm{T}$, et al. Surgical outcomes in juvenile retinal detachment. Jpn J Ophthalmol. 2001;45:409-11.

11. Weinberg DV, Lyon AT, Greenwald MJ, Mets MB. Rhegmatogenous retinal detachments in children: risk factors and surgical outcomes. Ophthalmology. 2003;110:1708-13.

12. Chen SN, Jiunn-Feng $\mathrm{H}$, Te-Cheng $\mathrm{Y}$. Pediatric rhegmatogenous retinal detachment in Taiwan. Retina. 2006;26:410-4.

13. Fivgas GD, Capone A Jr. Pediatric rhegmatogenous retinal detachment. Retina 2001;21:101-6.

14. Huang YC, Chu YC, Wang NK, Lai CC, Chen KJ, Hwang YS, et al. Impact of etiology on the outcome of pediatric rhegmatogenous retinal detachment. Retina. 2019;39:118-26.

15. Lee RW, Mayer EJ, Markham RH. The aetiology of pediatric rhegmatogenous retinal detachment: 15 years experience. Eye (Lond). 2008;22:636-40.

16. Wang NK, Chen YP, Yeung L, Chen KJ, Chao AN, Kuo YH, et al. Traumatic pediatric retinal detachment following open globe injury. Ophthalmologica. 2007;221:255-63.

17. Wang NK, Chen YP, Lai CC, Chen TL, Yang KJ, Kuo YH, et al. Paediatric retinal detachment: comparison of high myopia and extreme myopia. Br J Ophthalmol. 2009;93:650-5.

18. Wadhwa N, Venkatesh P, Sampangi R, Garg S. Rhegmatogenous retinal detachments in children in India: clinical characteristics, risk factors, and surgical outcomes. J AAPOS. 2008;12:551-4.

19. Soheilian M, Ramezani A, Malihi M, Yaseri M, Ahmadieh $\mathrm{H}$, Dehghan $\mathrm{MH}$ et al. Clinical features and surgical outcomes of pediatric rhegmatogenous retinal detachment. Retina. 2009;29:545-51. 
20. Read SP, Aziz HA, Kuriyan A, Kothari N, Davis JL, Smiddy WE, et al. Retinal detachment surgery in a pediatric population. Retina 2018;38:1393-402.

21. Smith JM, Ward LT, Townsend JH, Yan J, Hendrick AM, Cribbs BE, et al. Rhegmatogenous retinal detachment in children: clinical factors predictive of successful surgical repair. Ophthalmology. 2019;126:1263-70.

22. Oono Y, Uehara K, Haruta M, Yamakawa R. Characteristics and surgica outcomes of paediatric rhegmatogenous retinal detachment. Clin Ophthalmol. 2012;6:939-43.

23. Rahimi M, Bagheri M, Nowroozzadeh MH. Characteristics and outcomes of paediatric retinal detachment surgery at a tertiary referral center. J Ophthalmic Vis Res. 2014;9:210-4.

24. Agarkar S, Gokhale VV, Raman R, Bhende M, Swaminathan G, Jain M. Incidence, risk factors, and outcomes of retinal detachment after pediatric cataract surgery. Ophthalmology. 2018;125:36-42.

25. Al-Zaaidi S, Al-Rashaed S, Al-Harthi E, Al-Kahtani E, Abu El-Asrar AM. Rhegmatogenous retinal detachment in children 16 years of age or younger. Clin Ophthalmol. 2013:7:1001-4.

26. Errera MH, Liyanage SE, Moya R, Wong SC, Ezra E. Primary scleral buckling for paediatric rhegmatogenous retinal detachment. Retina. 2015;35:1441-9.
27. Gurler B, Coskun E, Öner V, Comez A, Erbagci I. Clinical characteristics and surgical outcomes of paediatric rhegmatogenous retinal detachment. Int Ophthalmol. 2016;36:521-5.

28. McElnea E, Stephenson K, Gilmore S, O'Keefe M, Keegan D. Paediatric retinal detachment: aetiology, characteristics and outcomes. Int J Ophthalmol. 2018;11:262-6.

29. Tsai A, Wong CW, Lim L, Yeo I, Wong D, Wong E, et al. Pediatric retina detachment in an Asian population with high prevalence of myopia. Retina. 2019;39:1751-60.

30. Chen C, Huang S, Sun L, Li S, Huang L, Wang Z, et al. Analysis of etiologic factors in pediatric rhegmatogenous retinal detachment with genetic testing. Am J Ophthalmol. 2020;218:330-6.

31. Fong A, Yip P, Kwok T, Tsang CW. A 12-year review on the aetiology and surgical outcomes of paediatric rhegmatogenous retinal detachments in Hong Kong. Eye. 2016:30:355-61.

32. Carranza-Casas M, Quiroz-Gonzalez E, Hernández-Reyes A, Matsui-Serrano R, Ariza-Camacho E, Graue-Wiechers F. Pediatric rhegmatogenous retinal detachment: predictors of anatomic and functional success. Int Ophthalmol. 2021 Apr 11. doi: 10.1007/s10792-021-01834-w. Online ahead of print. 